\title{
Fotografía y expresión femenina o el valor subversivo de la imagen: el caso de los "fotografismos" de Claire Lejeune
}

\author{
Cecilia FERNÁNDEZ SANTOMÉ \\ Universidad de Santiago de Compostela \\ Departamento de Filología Francesa \\ cfsantome@hotmail.es
}

Recibido: 7 de julio de 2009

Aceptado: 8 de octubre de 2009

\section{RESUMEN}

Este artículo aborda la relación entre la creación fotográfica, la evolución del canon artístico occidental y la proliferación de propuestas culturales subversivas. El nacimiento de la fotografía hundió en un cierto caos a los círculos intelectuales de la Europa de finales del siglo XIX. El cuestionamiento de los sistemas de representación vigentes y de la supremacía de la pintura, inestabilizó las rígidas posiciones existentes. Sin embargo, la fotografía ha transcendido la polémica para consolidarse como una nueva vertiente del arte moderno, sirviendo no sólo a la difusión de una cierta visión del mundo, sino a la subversión de la misma. Una línea muy atractiva para una intelectual como Claire Lejeune, cuya escritura "po-ética" expone la urgencia de la promoción de un nuevo orden social, político y artístico que incorpore a las miradas del silencio.

Palabras clave: Fotografía, arte, periferia, mujer, subversión.

Photograph, feminine expression and the power of images: a study on Claire Lejeune's "photographismes"

\begin{abstract}
This article aims to explain the relationship between photography, the western artistic canon, and subversive forms of expression. To a certain extent, the invention of photography wreaked havoc amongst European intellectuals in the last decades of the nineteenth century. By destroying the artistic supremacy of painting, photography fractured the traditional ways of representation. Now an essential form of modern art, photography has nevertheless outlasted those controversies from the past, thus becoming a useful instrument to explain or to subvert the world. Such ambivalence has been seductive for Claire Lejeune. Her "photographismes" represent an alternative technique to literary work whereby she presents her belief that it is necessary to join emergent voices.
\end{abstract}

Key words: Photograph, art, periphery, women, subversion.

La photographie, le discours féminin ou la valeur subversive des images: à propos des "photographismes" de Claire Lejeune

RÉSUMÉ

Cet article vise le rapport existant entre la création photographique, l'évolution du canon artistique occidental et la prolifération de courants culturels subversifs. La naissance et l'essor de la 
photographie plongea dans le chaos le plus absolu les milieux culturels européens du XIX ${ }^{\text {ème }}$ siècle. La mise en question des systèmes de représentation en vigueur et de la suprématie de la peinture bouleversa les prises de position traditionnelles. Pourtant, cette discipline a réussi à se situer au-delà de toute polémique, étant devenu tout un symbole des arts modernes au service non seulement de la transmission d'un certain regard sur la réalité, mais aussi à la subversion de celle-ci. Voilà un créneau très séduisant pour une intellectuelle comme Claire Lejeune, dont l'écriture poét(h)ique témoigne de la nécessité de promouvoir un nouvel ordre social, politique et artistique pour réhabiliter les regards du silence.

Mots clés: Photographie, art, périphérie, femme, subversion.

La fotografía, al igual que su hijo pródigo el cine u otras disciplinas artísticas contemporáneas como la pintura callejera, se ha visto confrontada a un largo proceso de legitimación y de consolidación dentro del canon artístico occidental. Nacida de los experimentos promocionados en la Francia decimonónica por Daguerre y perfeccionada por Beard y Talbot, entre otros, la fotografía parecía un simple pasatiempo burgués, un juguete para una sociedad de "narcisos todos" (en palabras de Charles Baudelaire).

Muchos artistas, llenos de optimismo, sostuvieron entonces que la fotografía "se mantendría en su sitio", y que funcionaría, sobre todo, como una especie de criada para todo el arte. Pero esta actitud resultó ser tan presuntuosa como fútil. El nuevo medio de expresión artística estaba [...] en rapport con la mentalidad de un amplio y creciente sector del público que se enorgullecía de sus logros mecánicos y, en parecida medida, con la preocupación, también creciente, de los artistas por la representación veraz [...] (Scharf, 1994: 15)

Frente a la supremacía de la pintura en la representación de modelos directamente extraídos de la realidad tangible, esta modalidad constituía una peligrosa alternativa. Peligrosa porque parecía alejarse de toda idealización, ciñéndose a la objetividad del mecanismo y neutralizando la subjetividad del realizador. Sin embargo, el carácter inmediato de la creación fotográfica (desde los largos minutos de exposición requeridos en los primitivos sistemas a la instantaneidad de la tecnología digital actual) hizo de la misma el arte de la modernidad, del frenesí vital y de la exaltación de la fugacidad del instante. El fotógrafo parecía amenazar entonces con convertirse en el nuevo pintor de cámara de las clases desahogadas que podían tener acceso a su "mágico" artilugio. Las características formales del retrato fotográfico (más ágil y fiel al modelo) que motivaron esa fascinación por un cierto auto-conocimiento complaciente alimentaron críticas y recelos casi siempre inmotivados, sobre todo por parte de los pintores y los artistas plásticos en general. Y es que las reacciones de los medios artísticos estuvieron frecuentemente mezcladas con la ironía del campeón derrotado que felicita a su vencedor (Scharf, 1994: 29).

A partir de ese momento, la relación entre ambas disciplinas se vio marcada por el prototípico esquema del dominante y el dominado. El peso de la tradición y de la historia cultural occidental otorgaba a la pintura, el grabado y la escultura una posición preeminente frente a cualquier otra técnica naciente. En la pirámide virtual 
que determinaba la jerarquía interna del campo artístico europeo, la fotografía parecía estar avocada a las posiciones marginales. Ésta carecía de legitimación, que sólo había de conseguir con el paso de las décadas y la difusión de sus resultados.

Los ocupantes de las posiciones centrales del sistema cultural en el que pretendían acomodarse sus inventores eran reticentes -por su propia naturaleza de ya consagrados- a toda innovación, dificultando las incorporaciones a su restringido círculo. Los habitus (Bourdieu, 1991) que regían el funcionamiento de las dinámicas propias del mismo divergían sustancialmente de las normas intrínsecas al trabajo fotográfico.

Este delicado contexto subrayaba lo periférico de la nueva arte. Una situación fácilmente extrapolable al también secundario plano en el que la mujer artista había desarrollado sus actividades intelectuales durante siglos. Reservado el ámbito público a la expresión masculina (ocupando el hombre la inmensa mayoría de las funciones de relevancia social), el terreno de la cultura bebía de ese mismo hermetismo.

Les usages publics et actifs de la partie haute, masculine, du corps [...] sont le monopole des hommes; la femme, qui [...] se tient à l'écart des lieux publics, doit en quelque sorte renoncer à faire un usage public de son regard [...] et de sa parole (Bourdieu, 1998: 23).

La literatura, la pintura o la escultura daban la espalda (en gran medida y salvo raras excepciones apenas reseñables) a esas voces femeninas que luchaban por abrirse camino, pero no disponían del capital simbólico o real necesario para lograrlo.

Fotografía y arte femenino eran, pues, dos modelos marginales, periféricos, desprestigiados por aquellos agentes culturales imbuidos del poder de legitimar o deslegitimar las propuestas de los recién llegados al medio en cuestión. Su única esperanza era la existencia por procuración, a través de otros integrantes sistémicos que permitiesen una entrada disimulada y progresiva en el terreno de la cultura occidental. Para ellos estaba reservado el espacio en blanco desechado por las fuerzas dominantes, canonizadas.

Siempre sometidos al debate público, la intelectual y el/ la fotógrafo/-a compartían un terreno yermo común, un vacío que amenazaba con convertirse en un agujero negro a partir del cual sería difícil consolidar nuevas posiciones. Paradójicamente, el alejamiento de todas estas propuestas con respecto a las cumbres del éxito comercial y artístico, se tornó en ambos casos en impulso creador. Du bon usage du néant: il est la clef magique menant à l'armoire secrète de la sagesse; il est le plus imprévu des compagnons: il devient sagesse, indifférence joyeuse à tout ce qui est inutile et dépourvu de sens (Russ, 1998 :16).

Uno de los principales focos de las críticas recibidas por los retratos fotográficos era su bizarro proceso de revelado, que hacía surgir de entre las nieblas la imagen tomada. Como si de un hechizo se tratase, la fotografía era tratada por sus detractores como un invento mágico, fruto de la brujería y las fuerzas maléficas. La intervención de una especial combinación de tiempos, de movimiento y de quietud, así como de procesos químicos complejos a los que la mayor parte de la población europea era ajena, otorgaban a la fotografía un aura de sacralidad demoníaca. 
Además, las fotografías son un género de alquimia, por cuanto se las valora como relato transparente de la realidad (Sontag, 2003: 94).

Una estrategia reaccionaria que comulgaba con la caracterización generalizada de aquellas mujeres que osaban entrar en un terreno tan marcadamente masculino como las ciencias y el estudio, rápidamente tachadas de hombrunas, bas-bleus, hechiceras heréticas que hacían peligrar el equilibrio social. El influjo de la expresión artística femenina tenía, pues, mucho en común con la nueva apuesta de los inventores europeos. Fascinaban, atraían y repelían por igual.

Curiosamente, esa familiaridad entre ambos sistemas se vio ensombrecida por el hecho de que, en un principio, la experimentación fotográfica permanecía tan ajena al trabajo femenino como el resto de las instituciones culturales. Daguerre, Niepce, Talbot no son más que algunos ejemplos de los pioneros -siempre hombres- que tuvieron ocasión de participar en el florecimiento de esta nueva fuente de expresión creativa. Incluso la experimentación periférica dentro del ámbito artístico estaba en manos de agentes masculinos, vedando este terreno a la mujer.

La necesidad de legitimar sus propuestas y hacerse con un lugar propio dentro del mercado de las obras culturales empujaba a la artista a buscar nuevas estrategias y recursos que explotar. Si bien Bourdieu afirma que

la force de l'ordre masculin se voit au fait qu'il se passe de justification: la vision androcentrique s'impose comme neutre et n'a pas besoin de s'énoncer dans des discours visant à la légitimer (Bourdieu, 1998: 15)

en el caso de la mujer, su mirada no sólo no está exenta de toda justificación, sino que debe llevar a cabo una díficil y constante labor de legitimación y de autoexplicación en aras de demostrar su valía y autenticidad.

A finales del siglo XIX, el movimiento de las sufragistas se extendía por el Viejo Continente, desde Inglaterra hasta Francia y clamaba por el reconocimiento de la capacidad intelectual y social femenina. Poco a poco, pioneras como Virginia Woolf, las hermanas Brönte o Jane Austen habían conseguido hacer oír sus voces en la literatura. Unas voces que, ya fuese en tramas románticas o modernistas, monologadas o dialogadas, contenían un profundo poso crítico, un double gaze (Abel, 1982) o fusión en una misma pluma dos ópticas: una más aséptica, novelesca; la otra, comprometida.

Y ese desdoblamiento ficcional encontró en la fotografía un campo abonado. No sólo por el paralelismo existente entre la perspectiva asociada a la visión y la lente de la cámara fotográfica, sino por los valores implícitos a la manipulación de la máquina. En efecto, ésta plasma una imagen, mas también da acceso a una idea de fondo, a un concepto, a un sentimiento. Existen en ella varios niveles interpretativos que pueden ser descubiertos o permanecer ocultos sin dañar la esencia del conjunto.

Y la fotografía, desde sus orígenes, al conseguir fijar corporalmente el tiempo, al detener visualmente el instante, al abrirse a nuevos espacios de visión, se ha convertido en un testigo de lo que acontece al individuo, a la sociedad, al mundo y a la historia. (Casajús Quirós, 1998: 31)

En sociedades como las modernas y contemporáneas, cuyos engranajes se debaten entre un movimiento narcisista que hace volverse al individuo hacia su 
propio reflejo espejado -congratulándose en la imagen proyectada- y una tendencia voyeurista que lo impulsa a penetrar en la imagen que los otros tienen de ellos mismos (convirtiéndolos en êtres regardés -Lacan, 1973: 71), el retrato se percibe como una fórmula rompedora con la que aprehender identidades, pues para los militantes la identidad lo es todo (Sontag, 2003: 18).

\footnotetext{
Vivimos en una sociedad voyeurista, donde se ha convertido en una forma de participar en los hechos y en la vida. El espacio se hace pequeño y el tiempo se desdobla para que podamos mirar cualquier acontecimiento lenta y diseccionadamente sin comprometernos ni mancharnos. [...]

Hoy día podemos ver y hacer fotografías lo mismo que podemos escuchar y hablar o escribir [...] (Casajús Quirós, 1998:13)
}

Sin embargo, la difícil posición ocupada por los agentes femeninos del campo cultural occidental ha bloqueado en parte esa pasividad frente a la representación. Muy al contrario, y viendo en la fotografía una fuente de innovación y de exploración artística, la mujer manifestó un interés temprano por las técnicas del daguerrotipo. La convergencia de los distintos niveles comunicacionales que alberga la fotografía, su sutil superposición, han permitido dar forma a la voz pública femenina. Bajo la anodina e inocente toma fotográfica y su estereotipada proximidad al modelo, la mujer hace circular su propia perspectiva, su visión y su selección de los elementos susceptibles de ser retratados. Les femmes, soumises à un travail de socialisation qui tend à les diminuer [...] font l'apprentissage des vertus négatives d'abnégation, de résignation et de silence [...] (Bourdieu, 1998: 55). A través de la duplicidad interpretativa de la imagen revelada, el camino hacia la palabra parecía allanado. De forma casi imperceptible y sin la relativa violencia (metafórica o real) que puede llegar a caracterizar la lucha por el reconocimiento de los semejantes, la mujer europea llevó a cabo su particular acercamiento a esta nueva técnica tanto o más controvertida que su propia presencia en ámbitos tradicionalmente masculinos.

Horadando los lindes del elitista círculo intelectual europeo, fotógrafas como Julia Margaret Cameron se esforzaron por llevar a otros ámbitos distintos hasta los entonces abordados el cuestionamiento de los cánones culturales heredados. Colaborando con sir Alfred Tennyson en la ilustración de una de las obras más célebres del poeta británico -Idylls of the King-, Cameron desarrolló su vocación artística a través del montaje y la recreación de ambientes y escenas de la Materia de Bretaña. Amigos y familiares colaboraron con esta fotógrafa aficionada en la realización de series de imágenes con un común denominador: el retrato de la mujer. Una figura central en sus composiciones que contribuyó a hacer de las mismas un material rico en interpretaciones, a menudo ambiguo y sugerente. En una palabra: subversivo.

Las representaciones de la Dama de Shalott, la reina Ginebra o los caballeros de la Tabla Redonda sirvieron para plasmar visualmente las leyendas poetizadas por Tennyson. Mas también permitían la difusión de la subjetividad de la fotógrafa, plasmada en su modo de leer el material de base con el que contaba. Calladamente, sin discursos grandilocuentes ni textos incendiarios, la mujer se sumaba al dolor de las damas retratadas. Las sombras, los sfumatos o las figuras desenfocadas de sus 
trabajos son la mejor expresión posible del rol secundario que nuestras sociedades han reservado durante siglos a la mujer. La fotógrafa parecía querer captar y plasmar -con el papel de revelado como soporte- las constricciones sufridas por sus congéneres, como si el uso de dicha técnica contribuyese en cierta medida a excarcelarla de las mismas.

La especial relación establecida entre la mujer y la fotografía desde prácticamente la invención de este nuevo soporte visual no se limitó a la práctica artística. En realidad, este arte hizo correr ríos de tinta entre las intelectuales femeninas en igual medida que entre los críticos masculinos. Por otra parte, es reseñable que, en el caso de éstas, las opiniones no eran en modo alguno tan abiertamente hostiles:

Las fotografías, asegura Woolf "no son un argumento; son simplemente la burda expresión de un hecho dirigida a la vista". La verdad es que no son "simplemente" nada, y sin duda ni Woolf ni nadie las consideran meros hechos. Pues, como añade de inmediato, "la vista está conectada con el cerebro; el cerebro con el sistema nervioso. Ese sistema manda sus mensajes en un relampagueo a los recuerdos del pasado y a los sentimientos presentes." Semejante prestidigitación permite que las fotografías sean registro objetivo y testimonio personal, trascripción o copia fiel de un momento efectivo de la realidad e interpretación de esa realidad [...] (Sontag, 2003:36)

Pero el tan comentado carácter objetivo de la representación fotográfica merece ser matizado. Evidentemente, ésta - mediante los procesos químicos en los que se basa- permite realizar una reproducción de su modelo mucho más fidedigna que la pintura. La aparente asepsia de la fotografía queda expresada en palabras de Casajús Quirós del modo que sigue:

¿Qué es la fotografía? [...] Grabar una imagen no nacida de la habilidad manual y visual del pintor, sino una imagen que se forma "sola", gracias a la luz y que se hace permanente gracias a las reacciones fotoquímicas sobre determinadas substancias. (Casajús Quirós, 1994: 19)

Sin embargo, la técnica empleada, la perspectiva adoptada, la estética preferida por el autor del cuadro introducían modificaciones más o menos ligeras con respecto a lo reflejado en el cuadro. Las texturas, las calidades, los claroscuros y las luces contribuían a dotar de realismo o de idealismo a las composiciones.

La inmediatez de la producción fotográfica, la exposición directa, breve, y casi explosiva a la mirada del fotógrafo parecían relativizar o minimizar el posible alejamiento entre el resultado final y el punto de partida. En efecto, ésa era la tónica habitual en los primeros desarrollos de la fotografía. De todos modos, no debe excluirse un principio fundamental:

La objetividad pura es una utopía, la traducción literal del objeto real queda excluida. Puede que la actitud del fotorreportero sea la de reproducción, pero el resultado no es reproducción sino representación en la que se manifiesta la personalidad del autor. (Sontag, 2003: 31)

El carácter mimético asociado tradicionalmente a la pintura parecía desplazarse, así pues, sobre el nuevo eje fotográfico. Boccioni (1913) reflexionaba de modo muy crítico y un tanto condescendiente sobre esta tendencia: 
Siempre hemos rechazado con asco y desdén incluso la más lejana vinculación con la fotografía, porque se encuentra fuera de los límites del arte. La fotografía tiene valor en la medida en que, reproduciendo los objetos e imitando objetivamente, ha conseguido, gracias a su perfección, liberar a los artistas del peso de reproducir la realidad con precisión. (Scharf, 1994: 276)

La lente fotográfica, el objetivo y sus modulaciones permiten una gama tal de variaciones y de manipulaciones de la realidad captada que toda tentativa de objetividad puede verse automáticamente difuminada. El ojo humano, subjetivo, interesado, curioso y creativo, encuentra en la tecnología un aliado óptimo del que echar mano no sólo para plasmar una realidad, sino para transmitir su propia configuración de dicho universo. Y es que siempre es la imagen que eligió alguien; fotografiar es encuadrar, y encuadrar es excluir (Sontag, 2003: 57). Seleccionando una pose para la figura retratada, disponiendo los elementos presentes en las imágenes de naturalezas muertas, etc. es el propio ego del o de la artista quien se muestra.

El arte femenino occidental se ha visto afectado por el cliché de la imitación. Basándose en la pretendida incapacidad de la mujer para producir modos de expresión cultural propios, sus propuestas se veían sometidas a un análisis en calidad de simples copias de las formas en boga en cada período concreto. De la artista se esperaba una actitud mimética, como si de un burdo falsificador de obras de arte se tratase. Luce Irigaray subraya, a propósito de esta cuestión, que las intelectuales se han visto históricamente contraintes à une mimétique défensive ou offensive (Irigaray, 1985: 318).

No obstante, si la mujer se ha plegado a las normas o hábitos propios a un determinado movimiento o corriente, no lo ha hecho movida por la simple voluntad de beneficiarse del éxito de las fórmulas ajenas mediante una relación parasitaria, sino más bien simbiótica. Si la escritora decimonónica ha seguido las reglas del romanticismo o del realismo, si la pintora ha hecho suyos los trazos discontinuos del impresionismo o si se ha arriesgado a practicar el nuevo arte de la fotografía, ha sido en busca de una tribuna de expresión legítima y legitimada. La mimesis consciente o no- esconde una pretensión mucho más ambiciosa: la tentativa of revision, appropriation, and subversion that constitute a female texte (Abel, 1982: 2).

Uniendo mímesis, intención subversiva e innovación, parece más que fundamentado el interés de las artistas por el trabajo fotográfico. Las posibilidades expresivas y creativas del mismo permiten la canalización de la subjetividad de su autora. Es así como la mujer artista ha conseguido incorporar su propia óptica a los círculos intelectuales europeos. Una mirada doble que resulta de la combinación estratégica del visor de enfoque y de la perspectiva inherente a la imagen resultante.

Habiéndosele atribuído a la obra femenina el estigma de ser subjetiva, sentimental y emotiva, ¿qué mejor modo de revertir dicho lugar común que mediante la explotación del arte más rabiosamente moderno, versátil, subjetivo, transformador y subversivo? La fotografía ha contribuido de manera muy considerable a una situación como la actual, en la que puede existir simultáneamente una heterodoxia de estilos artísticos (Scharf, 1994: 332). El esfuerzo por invalidar el constrictivo canon artístico occidental ha desplazado a la fotografía desde los márgenes del sistema -en los que comenzó su andadura 
decimonónica- para hacer de ella un instrumento alternativo y rico en expresión. Complementando otras modalidades artísticas, la imagen contiene hoy un valor añadido no desdeñable.

Y si la fotografía se ha convertido en el arte de mayor proyección a lo largo del siglo pasado, el terreno de la escritura ha asistido a procesos similares de emergencia y visibilización de fórmulas no canónicas como son la literatura femenina, homosexual, étnica o colonial. Éstas se han erigido en realidades cuyo prestigio creciente ha oradado la rigidez del campo cultural occidental. Así, el proceso de demistificación de las artes a lo largo del siglo XX ha producidouna apertura de la mirada crítica, tendiendo puentes hacia una cierta "democratización" de la experiencia artística gracias a la flexibilización del acceso a la misma.

La fotografía es la única de las artes importantes en la cual la formación profesional y los años de experiencia no confieren una ventaja insuperable sobre los no formados e inexpertos: por muchas razones, entre ellas la importante función que desempeña el azar (o la suerte) al hacer las fotos, y la inclinación por lo espontáneo. (Sontag, 2003: 38)

El fácil acceso a la maquinaria fotográfica y lo elástico de su práctica permiten la difusión y la popularización de este arte. Ello no implica que cualquier aficionado disponga de los resortes necesarios para ser capaz de colocar en el mercado de los bienes culturales sus imágenes, pues todo ámbito se ve regido por una serie de habitus que deben ser conocidos, respetados y sin los cuales, el realizador puede ver comprometida su posición dentro de ese terreno. Sin embargo, puede considerarse como un creador en potencia. El cuestionamiento de las normas vigentes operado por la fotografía se sitúa en la línea casi deconstructiva iniciada por movimientos como el Dadaísmo, Surrealismo o el Cubismo. Nuevas fórmulas y formas, nuevas sensibilidades y nuevas voces afloran desde principios del siglo XX en torno a esta brecha, a esa brizna de aire fresco.

Incluso la propia pintura ha evolucionado, bebiendo de fuentes insospechadas como la propia fotografía. Objetiva o subjetiva, ha superado las fronteras que la separaban de otras disciplinas para colaborar en la generación de un arte casi total. ¿Acaso no son un buen ejemplo de ello los trabajos de Andy Warhol? El artista que desmitificó el concepto de modelo en el arte, retratando simples latas de Sopas Campbell o concibiendo cuadros- retrato sobre la base de infinitas combinaciones de variantes cromáticas. Pintura y fotografía conviven en sus obras, llamadas a representar la cultura popular y que en pleno siglo XXI ocupan las salas de algunos de los museos y galerías más importantes del mundo como el Grand Palais parisino.

Ese acercamiento del arte a las masas, dejando atrás un cierto proselitismo cultural, está íntimamente relacionado con la expansión de movimientos sociales críticos en favor de la superación de los parámetros ordinarios de categorización social. El progreso de la democracia institucional en Europa y en todo Occidente ha permitido el acceso a los parlamentos de amplios sectores cívicos hasta ese momento minorizados.

Témoin de la présence simultanée d'une tendance à l'intégration, d'une montée des nationalismes et d'une multiplication des revendications identitaires, la fin du $20^{\mathrm{e}}$ siècle est marquée au sceau des tensions entre universalismes et particularismes. (Karmis y Gagnon, 1996 : 435) 
Universales y particulares que habitan también los textos de una de las pensadoras y poetas más laureadas del ámbito francófono: Claire Lejeune (19262008). Aunque su faceta más destacada ha sido la de ensayista y crítica cultural, su obra fotográfica merece una mención especial. Algunos de sus trabajos literarios más célebres como son Âge poétique, âge politique (1987), Le livre de la soeur (1993) o Le livre de la mère (1998) reflejan su interés por el estudio de las disposiciones sociales y culturales que determinan y condicionan la formación de la identidad femenina. Un profundo compromiso ético y poético estructura sus textos: el interés por el esclarecimiento de las circunstancias que han favorecido la consolidación del patriarcado en Occidente, entendido como sistema sociopolítico fundado en valores excluyentes y exclusivos e imbuido de la fuerza legitimadora asociada a la moral tradicional, la religión y la costumbre.

Tomando el testigo de esa hornada del feminismo intelectual francés más combativo representado por Hélène Cixous, Luce Irigaray o Julia Kristeva, Lejeune no cejó en su empeño de renovar las vías de expresión a su alcance. La literatura y la filosofía actuaban en sus textos como dos disciplinas simbióticas, complementarias y necesarias. Su objetivo primordial era la consecución de una cierta solidaridad en el reparto del conocimiento y el saber atesorados por el ser humanos, para lo cual se requería la búsqueda de un justo equilibrio entre los polos de la dialéctica sexual convencional. Un punto intermedio que no sería más que el resultado alegórico de la materialización de nuevos cauces de diálogo social. ¿Cómo dar curso a esta necesidad de conciliación? Para hallar una fórmula adecuada, así como para refinar su propia cosmovisión, Claire Lejeune, ávida de experimentación, buscó en todos los moldes artísticos a su alcance.

La creación literaria de Lejeune se aparta voluntaria y conscientemente de toda regla preestablecida en relación al género elegido. En este sentido, no sólo podría hablarse de una clara tendencia a la experimentación, sino de toda una voluntad "iconoclasta" aplicada a la demolición de los valores canonizadores asociados al respeto de la norma dentro del ámbito de la producción cultural. Rehuyendo de cualquier tipo de limitación a la hora de modelar su discurso, Lejeune produjo una versión arriesgada y fascinante del ensayo tradicional. Hecho de retazos y fragmentos más o menos inconexos que seducen y repelen al lector en un baile desigual de conceptos e ideas que se renuevan y se recuperan sin cesar, el ensayo redescubre en su pluma su esencia etimológica, convirtiéndose en una "tentativa", un "proyecto", un "esbozo". Complementándose entre sí como si de una cadena infinita de pensamientos se tratase, los ensayos poéticos (tal es el subtítulo que reciben en gran parte de sus ediciones) de Lejeune reescriben, matizan y trazan el mensaje de la utopía concebida por la autora: el adviento de la sociedad fraternal.

Sus obras intentan dar cabida a un sistema poético-filosófico de gran envergadura que plantee una alternativa válida al racionalismo patriarcal. $\mathrm{Su}$ producción literaria -ya sea en poesía, ensayo o teatro- es, pues, un campo de experimentación dialógica. Pero, para llevar a cabo el perfeccionamiento de esta pedagogía de la nueva era no basta con la acción limitada del verbum. Si la mayor parte de sus obras emplean como molde el aforismo y la sentencia, ese mismo carácter sucinto, breve, explosivamente evocador por sus mismas limitaciones 
influencia su trabajo como fotógrafa, ya que la fotografía es como una cita, una máxima o un proverbio (Sontag, 2003: 31).

Siguiendo la estela de la ya mencionada Julia Margaret Cameron o de la propia Susan Sontag, Claire Lejeune descubrió en la fotografía el complemento ideal a sus ensayos. Su personal interpretación de los mismos (muy lejos de la tradicional rigidez de la disertación) se ha visto traducida en una también particular lectura de la imagen fotográfica. L'image prit valeur de promesse d'abord, de projet ensuite (Lejeune, 1966: 146-147). Para ella, la experiencia del lenguaje verbal no dista demasiado del juego que posibilita el lenguaje de lo visual. Martine Renouprez explica que :

Claire Lejeune s'aménage une chambre noire en 1968 pour reproduire à loisir cette alchimie de l'image qui lui semble si proche de l'alchimie des mots. Car l'écriture comme la photographie ont ce prodige de pouvoir reproduire à l'infini l'événement unique et de lui conférer un sens. (Renouprez, $2005: 48$ )

Y de ese largo proceso de búsqueda fotográfica surgen sus photographismes, una escritura en forma de imagen que irá perfeccionando con el paso de los años y que conseguirá exponer en numerosas ocasiones. A partir de 1970, su obra visual se dará a conocer no sólo en su Bélgica natal, sino también en Japón, en Francia y en Québec. Pero el suyo es el camino de la autodidacta, de la creadora naïve, condición que -excluyéndola en principio del engranaje historicista que garantiza la adecuación e inserción plena en la estructura de un determinado campo cultural según Bourdieu, 1991- podría haber condenado al fracaso su faceta de fotógrafa. Gracias en parte al capital simbólico obtenido de su actividad literario-filosófica, sus fotografismos autodidactas gozaron también del interés crítico.

Ella, que siempre había definido su llegada al terreno de la escritura como la única vía de reconciliación con su sombra, con esa otra desconocida en sí misma, desarrolló una estética fotográfica hecha de claros y oscuros, basada en la técnica de la solarización. La escritura parecía no ser ya suficiente para albergar y encauzar su desbordante torrente de reflexión y estudio.

En photographie, sans anéantir totalement l'image, le procédé de solarisation renvoie la représentation à une autre réalité imperceptible à l'œil nu. Techniquement, il s'agit au moment où s'achève la révélation du négatif dans la chambre noire, d'illuminer celle-ci d'un éclair de lumière blanche. Ce procédé permet d'inverser les noirs et les blancs du négatif, et d'en souligner le contour. Mais le développement de Claire Lejeune se double d'une autre opération, celle du contretype qui consiste à photographier le négatif obtenu, à le solariser à son tour et à créer ainsi un cliché négatif où, non seulement s'est produite l'inversion de l'inversion, mais la génération entre les noirs et les blancs ainsi travaillés par la lumière d'une matière nouvelle, d'une "valeur tierce" qui traduit (sur papier photographique) le contraste initial par une gamme de gris, un corpus de nuances inédites où se relativise l'opposition des "valeurs" contraires. (Renouprez, 2005: 50)

Lejeune pretendía hacer de sus imágenes un manifiesto subversivo, que invierte tendencias, matiza percepciones y blanquea superficies. Su subversión presenta una naturaleza doble, operando sobre distintos niveles. En primer lugar, se trata de una subversión -o inversión- en sentido literal, pues no en vano su técnica fotográfica se basa en la alteración voluntaria de la polaridad ordinaria en el revelado de las 
imágenes. Al mismo tiempo, se trata de una subversión intelectual, artística, ideológica, fundamentada en esta propuesta visual que viene a materializar, a hacer cuerpo del contenido abstracto de sus ensayos experimentales. Su fotografía es la exaltación y el testimonio del valor efectivo de los contrastes, así como del equilibrio inestable entre ambos contrapuntos. Así, podría hacerse extensible a sus fotogramas la afirmación : je traduisais en noir ce que tes blancs me disaient et tu me renvoyais au nom de la vérité blanche (Lejeune, 1993: 46). El blanco y el negro es en ella el balance de opuestos que convive en nuestras sociedades, en las que se juega un pulso entre el matriarcado derrocado y el patriarcado triunfante. La mezcla de ambos tonos invitaría a la superación de dicha dialéctica, dando lugar a un nuevo orden ético y social. La inversión de la perspectiva dominante coincidiría con la esencia de la solarización practicada:

Le processus photographique passe par un nécessaire renversement de perspective : le négatif est la face inverse de la révélation qui sera positive. Ce renversement incite la poète à percevoir la face cachée des êtres et des choses, à provoquer l'émergence de leur ombre, de ce sens opposé voir contradictoire présent en eux. (Renouprez, 2005: 54)

La alternancia entre espacios en blanco y fragmentos oscuros tiende un puente entre su escritura ensayística y sus fotografismos. Del tono categórico asociado a la máxima filosófica (en su caso, toda una sublimación del tradicional silencio y la urgencia del discurso femenino) a la rotundidad de la imagen distorsionada por la solarización, el fotografismo es el clímax de la escritura de Lejeune. Un acto subversivo que condensa laesencia de su concepción ético-estética. De este laboratorio de formas no sólo se extraen los fotografismos, sino también sendos capítulos en dos de sus obras más célebres: L'issue (1980) y L'œil de la lettre (1984).

Sous le titre d'“Analphabet", la partie centrale de L'issue est occupée par une quinzaine de photographies. Dans L'œil de la lettre, une partie intitulée "De mémoire d'arbre et de chardon", nous présente une succession de photographies évoluant du figuratif au non-figuratif. (Frickx y Trousson, 1988: 246)

Rompiendo la literalidad de los textos ensayísticos, se abre pues un paréntesis a una sucesión de imágenes en aparente décalage con la materia filosófica y que, precisamente por su extrañeza, contribuyen a avivar la capacidad crítica y analítica del lector potencial. Les livres de Claire Lejeune explorent et exploitent des réseaux d'images très riches et très complexes mais somme toute assez limités (Paquin, 1995: 94). Todo ello sirve para subrayar que: un rapport existe entre le créativité linguistique de la poésie et celle, iconique, de la photographie (Frinckx y Trousson, 1988:: 246). Simultaneando ambos procesos creativos, hace valer un mismo patrón regido por un esquema eminentemente dual: negro-blanco, texto-espacio intermedio. En ambas obras, la analogía entre escritura y fotografía no es un mero recurso estético, sino un eslabón perfectamente insertado en un proyecto general de naturalez ético-alegórica. Si la suya es une écriture où les analogies joueront un rôle déterminant (De la Torre Giménez, 2007: 270), la fotografía y la palabra se hermanan en una conjunción de elementos pictórico-poéticos que encarna una toma de posición concreta y real sobre la norma "po-ética". Se trata, en última instancia, 
de una llamada a la disidencia moral en favor de la disolución de los valores asociadaos a la mirada patriarcal como único punto focal, reclamando la incorporación legítima de otras perspectivas.

$\mathrm{Y}$ es que, su cuestionamiento de los moldes de producción cultural convencionales tanto en la prosa como en la fotografía, la autora belga provoca una revolución extrapolable al plano de la teoría social y del arte. Haciendo suyo en parte el cuestionamiento surrealista de las directrices artísticas modernas, así como de la propia naturaleza del arte y de sus fundamentos,

Par l'étrangeté du renversement des contrastes qu'ils offrent au regard, les photographismes de Claire Lejeune renvoient immanquablement à un questionnement relatif à la pratique de la création. (Renouprez, $2005: 51-52$ )

Pero la proximidad evidente entre escritura y fotografía no sólo se traduce en el formato textual elegido, sino que los propios ensayos parecen albergar una especie de memoria común de esa naturaleza dual de la prosa de Lejeune, dándole libre curso mediante alusiones directas a términos técnicos estrechamente vinculados al lenguaje de la fotografía profesional. Así, por ejemplo, [...] le vocabulaire technique de la photographie insémine le texte: "fixation", "révélation", "exposition", "point de vue", "distance focale", pour construire des métaphores filées (Renouprez, $2005: 48$ ).

Todo ello hace que la fotografía en Claire Lejeune trascienda el terreno de la mera afición del amateur para convertirse en un elemento más y nada desdeñable de su particular universo intelectual. Lejeune pretende invitar a la reflexión, activando los adormilados resortes intelectuales de la sociedad occidental. Y, para ello, la escritura y la imagen constituyen dos tribunas de excepción. Susan Sontag concluye que:

Al contrario de la crónica escrita -la cual, según la complejidad de la reflexión, de las referencias y el vocabulario, se ajusta a un conjunto más amplio o reducido de lectores-, una fotografía sólo tiene un lenguaje y está destinada en potencia a todos. (Sontag, 2003: 29)

Desde los márgenes del sistema cultural occidental, la fotografía y la poiesis femenina han iniciado una lenta evolución paralela (y, en ciertos aspectos, tangente, tal es el caso analizado en este artículo) que no sólo ha contribuido a su legitimación, sino también a su consolidación como dos fórmulas culturales de creciente ascendente entre los llamados "movimientos emergentes". Estos han sido claves en la evolución de los paradigmas sociales contemporáneos en favor de la producción de sistemas de pensamiento más próximos a la noción de "diferencia". La "alteridad" es, pues, la musa de la fotografía subversiva de Claire Lejeune, el objeto de culto de un sistema de representación verbal y visual que bien podría responder al lema: "ut photographia, poesis". 


\section{REFERENCIAS BIBLIOGRÁFICAS}

ABEL, E. (ed.). (1982): Writing and sexual difference, The Harvest Press, Sussex.

BOURDIEU, P. (1991): "Le champ littéraire" in Actes de la recherche en sciences sociales, Vol. 89, $\mathrm{N}^{\circ} 1,3-46$.

- (1998): La domination masculine, Seuil, París.

CASAJÚS QUIRÓS, C. (1998): Manual de arte y fotografia, Editorial Universitas, Madrid.

DE LA TORRE GIMÉNEZ, E. (2007): "Reseña de Claire Lejeune. La poésie est en avant, de Martine Renouprez" in Francofonía, No 16, 269- 271.

FRICKX, R. y R. TROUSSON. (1988): "CEil de la lettre (1')" in Frinckx, R. y R. Trousson. Lettres françaises de Belgique. Dictionnaire des oeuvres. IV, Duculot, París, 246.

IRIGARAY, L. (1985) : Parler n' est jamais neutre, Les Éditions de Minuit, París.

KARMIS, D. y A.- G. GAGNON. (1996) : "Fédéralisme et identités collectives au Canada et en Belgique: des itinéraires différents, une fragmentation similaire" in Canadian Journal of Political Science / Revue canadienne de science politique, Vol. 29, $\mathrm{N}^{\mathrm{o}} 3,435-468$.

LACAN, J. (1973) : Le séminaire. Livre XI. Les quatre concepts fondamentaux de la psychanalyse, Seuil, París.

LEJEUNE, C. (1966): La geste, José Corti, París.

- (1993) : Le livre de la sœur, Éditions Labor, Bruselas.

PAQUIN, J. (1995): "Pensée et expression poétique dans les essais de Claire Lejeune" in Études littéraires, Vol. 28, No 1, 93- 102.

RENOUPREZ, M. (2005): Claire Lejeune. La poésie est en avant, Éditions Luce Wilquin, Bruselas.

RUSS, J. (1998) : Le tragique créateur. Qui a peur du nihilisme?, Armand Collin, París.

SCHARF, A. (1994): Arte y fotografia, Alianza Editorial, Madrid.

SONTAG, S. (2003): Ante el dolor de los demás, Alfaguara, Madrid. 